\title{
Cognitive analytics management of the customer lifetime value: an artificial neural network approach
}

\author{
Marco De Marco \\ International Telematic University Uninettuno, Roma, Italy \\ Paolo Fantozzi \\ Sapienza University of Rome, Rome, Italy \\ Claudio Fornaro and Luigi Laura \\ International Telematic University Uninettuno, Roma, Italy, and \\ Antonio Miloso \\ Expertlab, Roma, Italy
}

\begin{abstract}
Purpose - The purpose of this study is to show that the use of CAM (cognitive analytics management) methodology is a valid tool to describe new technology implementations for businesses.

Design/methodology/approach - Starting from a dataset of recipes, we were able to describe consumers through a variant of the RFM (recency, frequency and monetary value) model. It has been possible to categorize the customers into clusters and to measure their profitability thanks to the customer lifetime value (CLV).

Findings - After comparing two machine learning algorithms, we found out that self-organizing map better classifies the customer base of the retailer. The algorithm was able to extract three clusters that were described as personas using the values of the customer lifetime value and the scores of the variant of the RFM model. Research limitations/implications - The results of this methodology are strictly applicable to the retailer which provided the data.

Practical implications - Even though, this methodology can produce useful information for designing promotional strategies and improving the relationship between company and customers.

Social implications - Customer segmentation is an essential part of the marketing process. Improving further segmentation methods allow even small and medium companies to effectively target customers to better deliver to society the value they offer.

Originality/value - This paper shows the application of CAM methodology to guide the implementation and the adoption of a new customer segmentation algorithm based on the CLV.
\end{abstract}

Keywords Customer base, Clustering, Customer lifetime value, Machine learning, Neural network

Paper type Research paper

\section{Introduction}

In the 1990s, marketing systems were forced to adapt and evolve due to the globalization and the tech innovation of those years (Chalmeta et al., 2001).

The globalization caused the openings of markets that were flooded by competitors from all over the world, as well as access for companies to new customers, previously unreachable (Di Taranto, 2013).

Similarly, technological innovation helped by profoundly changing the process structures of those years and allowing them to manage increasing volumes of information present within companies. Thanks to this phenomenon, the first ERP (enterprise resource planning) was developed (Spagnoletti et al., 2015).

Marketing strategies were profoundly affected by those changes in a way that the overall concept of marketing itself has been influenced. If in 1991 a BusinessWeek article defined the

CAM of the customer lifetime value

Received 28 January 2020 Revised 29 May 2020 10 August 2020 12 October 2020 Accepted 6 December 2020 
"perceived value" as the core for marketing strategies (Power et al., 1991), the evolution of the businesses happening during those years would have ushered in a revolution in the way marketers would do their job in the next few years.

New tools were developed to support the business in strategic planning and to manage the standardized process within organizations (decision support systems) (Jao, 2010; Jian, 2004; Kayande et al.,2006). Among those applications, some were developed with a specific focus on relationship marketing (Gummesson, 2002) and handled all the aspects related to it, to create a new category of applications: the customer relationship management systems (Iriana and Buttle, 2006).

In the following years, thanks to the analytical tools available to companies, marketing researchers began to devote interest to the "nature of value" (Holbrook, 1994). Marketing researchers now have the tools to finally violate the concept of customer value. Customer value is a construct made up of different components, most of them not directly measurable. For this reason, a different approach has been theorised in the literature to assess how valuable a customer is to a company (Holbrook, 1994; Kumar and Reinartz, 2016; Ulaga and Chacour, 2001; Yi and Gong, 2013).

This study proposes a methodology for estimating customer value thanks to the customer lifetime value, a metric that will be calculated through a consumer migration model and that will allow clustering companies.

It should also be clarified that the analysis carried out is not a mere theoretical demonstration of the validity of these methodologies but a real study conducted with the courteous and essential contribution of an Italian company operating on a national scale in the large-scale retail sector. In compliance with the protection of its privacy and that of its customers, the company has provided its data for academic purposes.

The company's goal was to verify if there was a way to improve the value offered to its consumers by maintaining or increasing the shared value already generated. Therefore, the CAM (cognitive analytics management) methodology was selected as the right framework, not only to better approach the problem but also to generate insights and suggest policies to management to guide the implementation of new methodologies for customer segmentation and value creation (Osman et al., 2019). Each of the three pillars of the methodology (cognitive, analytics and management) will be treated in a specific paragraph with exception of the section on management, which will coincide with the discussion.

The purpose of the study was to test a new customer segmentation methodology capable of providing useful insights for the management about its customer base. We tested two possible algorithms to evaluate which one was best suited to describe the customer base.

This paper is organized as follows: the next section provides the necessary related background and state of the art for both the CAM methodology (Section 2.1) and customer relationship management (Section 2.2). Then the methodology is described (Section 3) according to CAM, providing cognitive (Section 3.1), analytics (Section 3.2) and management (Section 3.3), whose results are detailed in Section 4. Finally, after a brief discussion (Section 5), Section 6 addresses conclusive remarks.

\section{Theoretical background}

\subsection{CAM methodology}

CAM methodology was designed to bring together the concepts of cognitive, analytics and management "to guide the implementation of digital transformation to address an organization's challenge" (Osman et al., 2019). Even if it is a recent approach and the literature around it is not widely developed, CAM is currently being used to assess e-services from users and providers' perspectives in the UK, Qatar and Lebanon. The goal is to 
modernize government services, increase e-participation, reduce corruptions and increase transparency to achieve sustainable growth of shared values for a smarter world.

The framework is divided into three processes: cognitive, analytics and management. The first process, cognitive, deals with the understanding of the challenge, acquiring the available knowledge on the matter to frame it into analytics terms. The second process, analytics, analyzes real data through descriptive, prescriptive and predictive analysis, and then it applies different methodologies from fields such as artificial intelligence, behavioral psychology, data science, data mining and deep machine learning. The last process, management, deals with the managerial implication of the examined themes and findings; it translates the results of the cognitive and analytics process into actionable strategies and goals, to create shared value among stakeholders.

The CAM Methodology represents a well-suited tool to deliver business insight to stakeholders. As far as corporate communication is concerned, the ability to manage the relationship between companies and stakeholders represents a key attribute that in the long run could represent a fundamental competitive advantage. Furthermore, the strong contribution of different areas of knowledge allows us to combine skills for a higher purpose that must consider the ultimate goal of research itself: to create value for the community.

The author of the methodology declared that: "Shared values are often created using innovative ideas based on the interface of measurement and management to balance the various trade-offs when making long and short term transformative decisions" (Osman et al., 2019; Osman and Anouze, 2014).

\subsection{Customer relationship management (CRM)}

CRM is based on the principles of relationship marketing which are the main area of development of modern marketing (Rahimi and Kozak, 2017). The idea behind this concept is to create value not only from the sporadic contact between the customer and the company at the time of purchase but to create an ongoing relationship between the two to maximize shared value. To correctly manage this CRM process, a fusion of relationship marketing and management theories and approaches (Gummesson, 2002) has been developed. In particular, thanks to these concepts it is possible to define a category of data-driven software that improves the way companies manage customers.

CRM was designed in the early 90 s, and its first application was intended to perform all those tasks related to marketing which were possible to standardize, such as customer segmentation, customer data management, customer previous purchase modelling, sales management and direct marketing (Bygstad and Presthus, 2012). The design of CRM intended to join a different software to provide all the aforementioned services, thus giving companies the power to control, track and evaluate customer data to better shape their relationships with the customer base (Aljawarneh and Al-Omari, 2018). The union of those different pieces of software in one system lead to the definition of customer relationship management systems, inspired by ERP systems, deemed to create a DSS (decision support system) capable of supporting the company internal agents in the relations with the external agents (stakeholders) (Jao, 2010; Jian, 2004; Kayande et al., 2006). CRM helps companies to manage and maintain stakeholders relationships through a series of innovative functionalities made possible by the data management process. This is the tool that enables companies to transform information into actionable insights (Barton and Court, 2012; Davenport et al., 2012). With the intensive use of algorithms, it is possible to collect data about the company market segment, archive them and use them accordingly to design-specific marketing strategies (Zerbino et al., 2018).
CAM of the customer lifetime value 
Some researchers affirm that CRM should be a philosophy for the company embodied inside its organizational culture and technology (Iriana and Buttle, 2006; Rahimi and Kozak, 2017; Ryals and Knox, 2001) to improve human interactions within the business environment (Greenberg, 2003). The growing importance of the network economy inside organizational assets has facilitated the rise of relationship marketing (Rollins and Halinen, 2005).

To establish a long-term and strong relationship with a stakeholder (which could be a partner, employee or customer) is necessary to acquire information about the stakeholder itself, model that information to understand it and, finally, plan a strategy to create the desired relationship.

Knowing information about "who he/she/it is", "how he/she/it relates with others" and "how he/she/it related with the firm in the past" allows modelling his/her/its behavior (Boulding et al., 2005; Galitsky and de la Rosa, 2011; Leuthesser and Kohli, 1995).

Unfortunately, planning a specific strategy for each stakeholder is not an easy task, and this is why a broader approach is used. Starting from a large group of stakeholders, agents with similar characteristics are grouped. (Jao, 2010; Jian, 2004; Kayande et al., 2006). The clustering approach is considered a cost-effective methodology for relationship management since not all the companies on the market have the expertise and the resources to operate a perfect segmentation competitively.

Describing customer behavior requires a broad understanding of customers and a model that is capable of explaining the observed phenomena with a certain accuracy. In the past, the RFM model has been used to understand customer purchasing patterns (Maryani and Riana, 2017). Thanks to its descriptive power, it is possible to describe the purchasing patterns by effectively providing useful insights on customers.

Those insights allow managers to better understand the market needs through their customer's behavior. In this way, it is possible to create a better value supply that does not only appeal to the mass market as a whole but each cluster of customers according to their patterns and value.

Only by understanding that consumers are not all the same it is possible to start treating them differently, following their needs to maximize not only the value offered to them but that shared with stakeholders.

Segmentation is the key to differentiate the offer and to better understand the needs of customers in their diversity. To do so, a model capable of describing customer value is needed to better target them with the appropriate marketing strategies.

One of the main objectives of marketing is maximizing value. Unfortunately, measuring value is not an easy task since it is composed of several variables that are difficult to measure effectively. Parasuraman sustained that: "Evidence confirming that the value assessment criteria and the process differs across the stages will have major implications for customer value theory and measurement" (1997).

From the customer's point of view, the value generated by the relationship with a company does not end during the moment of the transaction of a service or good. The value associated with a customer is generated in the entire relationship with the company.

Customer value is often measured with parameters such as LTV (life-time value), CLV (customer lifetime value) or CE (customer equity) (Kim et al., 2006).

According to Kotler et al. (2014), CLV is "the present value of the future profit stream expected over a given time horizon of transacting with the customer". The CLV is considered a forward-looking metric because it represents the present value of future cash flows associated with a customer (Pfeifer et al., 2005). Most empirical research on CLV have calculated customer value over past customer behavior (Fader et al., 2005). Various models have been developed in the literature for measuring CLV (Kumar and Reinartz, 2016). Among them is the customer migration model used by Dwyer which applied information extracted 
from the RFM model to evaluate the CLV (Dwyer, 1997). With this model, it is possible to predict consumer behavior on historical purchasing patterns (Fader et al., 2005).

\section{Methodology}

\subsection{Cognitive}

Nowadays, the digital world is evolving rapidly, and new technologies are applied in numerous economic areas. Therefore, it has become necessary and urgent for the marketing world to closely follow these evolving technologies and use them.

The goal is, first, to speed up the research and market analysis processes within the companies. It is no longer necessary to "show up at the door" of a prospect or collect answers for a survey (Stephens-Davidowitz and Pabon, 2017).

Considering the huge amount of data we are now immersed in, every interaction that people make with the digital world is stored somewhere and contains latent information about people's preferences, habits and passions.

Therefore, having access to these data means being able to know your customers, even before boring them with a survey to fill out. This consideration highlights a reality in which companies are increasingly focusing on the consumer before profit and create a sustainable value in which the customer feels privileged, important and considered. This generates value not only for the consumer but for the company as well (Zeithaml, 1988).

The key to loyalty is the ability to listen to the needs of its customers. Today, thanks to new technologies, it is also possible to identify what consumers have not yet explicitly expressed in terms of tastes and desires.

Thanks to the support of the company operating in the mass market, it was possible to analyze the customer's purchasing patterns through data on customer behavior. Thanks to data on the "when" and "how much" they spent, it was possible to acquire information about their purchasing patterns. An RFM (recency, frequency and monetary value) model was used to perform this activity because it provides an understanding of the customer's status inside the customer base. (Fader et al., 2005).

This model allows extracting useful KPIs (key performance indicator) on purchasing customer patterns and requires a small amount of easily accessible data (Tkachenko, 2015).

There are three components concerning the basic model, and each of them can be resumed with a specific question:

(1) Recency: how recently has the customer purchased?

(2) Frequency: how often do they buy?

(3) Monetary value: how much do they spend?

Furthermore, it has been chosen to integrate the RFM framework with two additional metrics introduced by Peker (Peker et al., 2017):

(1) Length: how long have they purchased?

(2) Periodicity: how often do they purchase?

As commented by Fader, the RFM model can show useful insights into a customer's buying pattern. For example, if a customer has visited the store frequently (high frequency) but it has been a long time since the last purchase (low Recency), it is possible to conclude that something has happened in the way the customer perceived the company. Therefore, the customer is unlikely to make another purchase in one of the company's stores (Fader and Hardie, 2009; Fader et al., 2005).
CAM of the customer lifetime value 
Thanks to the application of the LRFMP model, it would be possible to analyze the purchasing patterns. After that, it would be possible to measure the CLV of the members of the customer base according to their LRFMP score. This will provide a customer value assessment that will allow the company to conduct better customer segmentation.

\subsection{Analytics}

Carrying out a customer segmentation on customer data is possible thanks to the use of artificial intelligence since, in recent years, it has developed in a very advanced way of pattern recognition. In particular, thanks to machine learning it is possible to explain consumer behavior, to predict it and, consequently, better manage the consumer's needs. These data analysis and management tools are a boon for modern companies that want to interface optimally with customers to offer solutions suited to their needs. The goal is to improve not only the value among the customer base but among all stakeholders.

Therefore, analyzing the value of consumers and applying the latest machine learning algorithms techniques allow business managers, who compare and analyze data, to know, predict and manage consumer needs.

The growing production and circulation of data have allowed companies to be more aware not only of the reality that surrounds them but also of that within their own organization. In the past, the process of gathering information involved hiring someone to collect it manually. Nowadays the world is drowning in data collected through interconnected objects or IoT (Internet of Things) moving the challenge from "how to collect data" to "how to analyze them correctly" (Za, 2018).

Therefore, to measure CLV correctly and classify the customer base accordingly, we adopted a type of artificial neural network (ANN) trained through an unsupervised learning process: the self-organizing map (Kohonen, 1990).

The algorithm suited our purposes, but to better evaluate its results we applied another classification algorithm as a benchmark. The $K$-means has been chosen since it is one of the most popular unsupervised classification algorithms widely used in the literature (Arthur and Vassilvitskii, 2006).

3.2.1 Data processing. The records of over 850000 receipts issued in Rome in one year (April 2018-April 2019) compose the starting dataset. The dataset contains information on:

(1) Loyalty card identification number, anonymized by the company in compliance with the GDPR.

(2) Purchase amount expressed in euros.

(3) Timestamp stamped on the receipts.

The data have been cleaned from all the missing values and receipts with a purchase amount of less than $€ 0.40$ to clean up errors.

Starting from these data, we were able to create a new dataset of 60000 customers on which the variables of the LRFMP model have been calculated according to the formulas used by Peker (Peker et al., 2017).

3.2.2 LRFMP model. The RFM model is based on three dimensions. Recency $(R)$ is the time interval between the last purchase and the present time reference:

$$
\operatorname{Recency}(n)=\frac{1}{n} \sum_{i=1}^{n} \text { date_diff }\left(t_{\text {enddate }}, t_{m-i+1}\right)
$$

where date_diff $\left(t_{\text {enddate }}, t_{m-i+1}\right)$ represents the difference in days between the end date of the observation period ( $\left.t_{\text {enddate }}\right)$ and the date of a customer visit closer to $t_{\text {enddate }}$; and $t_{m}$ is the last 
visit of the customer and $n$ is the number of recent visits by the considered customer (Peker et al., 2017). Frequency $(F)$ is the number of customer purchases in a given period. Monetary value $(M)$ is the average amount spent by the customer over a given period.

The modified version of the RFM model used during this study considers other two variables: length $(L)$, which represents the duration of the relationship between the client and the company and periodicity $(P)$, which is a measure of the regularity of the customer's shop visits. Length is the measure of the difference in days between the last purchase and the first purchase in the period. The formula of periodicity is:

$$
\text { Periodicity }=\operatorname{stdev}\left(\mathrm{IVT}_{1}, \mathrm{IVT}_{2}, \ldots, \mathrm{IVT}_{n-1}, \mathrm{IVT}_{n}\right)
$$

where IVT represents the intervisit time or time between visits, and $n$ the number of visits minus one. IVT is the time between two consecutive purchases:

$$
\operatorname{IVT}_{i}=\text { date_diff }\left(t_{i+1}, t_{i}\right)
$$

where $i \geq 1$ and $t_{i}$ represents the date of the corresponding $i$-th visit of the customer (Peker et al., 2017).

The LRFMP model was preferred to the RFM model for the greater amount of information it is able to express for each individual customer. Furthermore, the five variables well suited to the retail market we are analyzing thanks to the completeness of the information greater than that verified in the standard model.

An LRFMP score can be calculated with the data relating to the individual variables. To proceed, it is necessary to assign weights to the four variables, as shown in the formula.

$$
\text { Model Score }=w_{1} L+w_{2} R+w_{3} F+w_{4} M+w_{5} P
$$

Although the weight of each RFM variable depends on the characteristics of the industrial sector (Stone, 1995), for this study we used the approach of Hughes (2000) assessing that the importance of the variables is equal.

3.2.3 Calculating the customer's value. Once all variables are calculated, it is possible to calculate the model score having a comparative metric of the value embodied by each customer within the customer base.

As discussed earlier, CLV is designed to be a forward-looking metric, even though no predictions have been made about customer future behavior in this case. The customer migration model used to link the RFM model to the CLV is based on past customer data. These data can provide information on the customer's likelihood of continuing to use the company's service or continuing to purchase its products and willingness to pay. With this information, it is possible to calculate customer value among the other customers within the customer base.

Using the same weight for each variable of the model (LRFMP) we calculated a CLV score. Since some of the variables are inverted variables with opposite signs, they have been reversed inverted in the CLV computing process.

Once the CLV is measured and integrated into the customer data dataset, it is possible to run the clustering algorithms and to compare the two to see which creates the best segmentation.

3.2.4 Clustering. Clustering is a subset of unsupervised learning techniques, and it is the process of grouping a set of data into classes with similar features.

One of the two clustering algorithms used during this study is $K$-means. $K$-means is the most used clustering algorithm in marketing. This algorithm was introduced by McQueen (MacQueen, 1967) and can quickly process large amounts of data.

Alternatively, the other clustering algorithm used is the self-organizing maps (SOM) or Kohonen's map, described later in the paper. 
We used the LRFMP model for clustering customers and determining the value of each customer. During the classification process, we identified the number of clusters based on the Davies-Bouldin index returned from the iteration of the SOM. The optimal number of clusters thus found $(k)$ has been used as a reference to perform the final clustering of both the algorithms and finally compare their scores. A comparison has been made between the $K$-means algorithm and the SOM to verify which method is more suitable for customer segmentation in this experiment.

The $K$-means algorithm has been chosen because of its popularity among statisticians in multiple fields of application, while the SOM has been used in very specific areas of application and is not largely used. Due to its specific nature, a strong comparison with a wellknown algorithm, such as $K$-means is required.

Subsequently, the classifications calculated by the two algorithms have been compared using the same Davies-Bouldin index. This comparison determined which classification to use for analyzing each customer's value.

3.2.5 Finding the K-optimum from the Davies-Bouldin index. After calculating the model variables and the CLV for each customer, the next step is customer segmentation using machine learning algorithms.

However, before starting the comparison, it is necessary to determine the number of clusters we are going to identify. Since improper selection of the number of clusters $k$ can lead to inaccurate results, there are useful clustering quality indexes that can help determine the optimal number of clusters.

For this purpose, we used the Davies-Bouldin index (Davies and Bouldin, 1979); this index aims to identify sets of clusters that have small variance within the cluster and a large variance between the same clusters.

The index represents the average of the similarity of the clusters to each other, where the similarity is measured as the ratio of within-cluster distances to between-cluster distances. Therefore, the more distant and less dispersed clusters will result in a better score.

In the definition of $R_{i, j}$ as the measure of a good clustering process, according to the definition above, the term $M_{i, j}$ indicates the variance between the $i$-th and the $j$-th cluster, while $S_{i}$ is, the variance within the cluster $i$. Hence, the Davies-Bouldin index is defined as the ratio of the sum of the within-cluster variances $\left(S_{i}+S_{j}\right)$ to the between-cluster variance $\left(M_{i, j}\right)$ :

$$
R_{i, j}=\frac{S_{i}+S_{j}}{M_{i, j}}
$$

The Davies-Bouldin Index is the system-wide average of the similarity measures of each cluster with its most similar cluster, where $R_{i}$ is the maximum of $R_{i, j}$ with $i \neq j$, and $N$ is the number of clusters. The "best" choice of clusters, therefore, will be the one that minimizes this average similarity.

$$
\mathrm{DB} \equiv \frac{1}{N} \sum_{i=1}^{N} D_{i}
$$

The smaller is the DB index associated with the cluster, the better the ranking. The SOM algorithm was run several times with $k$ ranging from 3 to 10 . Furthermore, since clustering algorithms are susceptible to the starting point, it has been decided to range this parameter through the random state. In this case, it has been varied between 1 and 10 for each iteration of the algorithm. This has been done to ensure greater validity of the process. We obtained the following associated indices that the means of the iteration per number of clusters: 


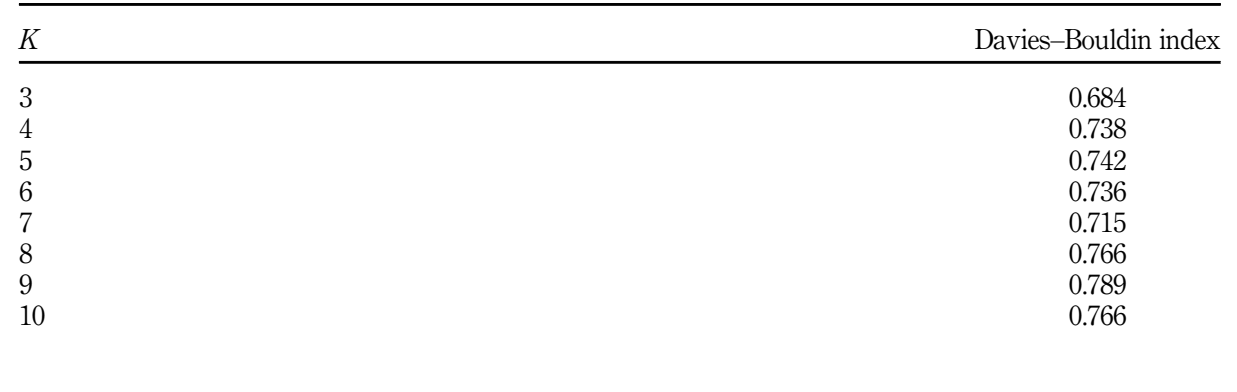

CAM of the customer lifetime value

Therefore, the number of clusters that minimizes the DB index is taken as the optimal number of clusters. After several iterations, the $k$-optimum was found to be 3 with a DB score of 0.437 .

3.2.6 Clustering by K-means. The $K$-means clustering is one of the oldest and most used clustering algorithms. After defining a number $k$ of clusters and the points within the dataset, the goal is to choose $k$ centers to minimize the total squared distance between each point and its nearest center.

Lloyd proposed a local search solution to this NP-hard problem, which is still very widely used today (Lloyd, 1982). A survey of data mining techniques states that it "is by far the most popular clustering algorithm used in scientific and industrial applications" (Berkhin, 2006).

$K$-means begins with arbitrary $k$ "centers," generally chosen randomly from the data points. Each point is then assigned to the nearest center, and each center is recomputed as the center of mass of all points assigned to it. These last two steps are repeated until the process reaches a local optimum. (Arthur and Vassilvitskii, 2006).

In Figure 1 is possible to see the cluster obtained where variables $P$ (periodicity), $L$ (length) and CLV (customer lifetime value) are used as axes because they seem to better represent the division of clusters operated by the algorithm.

3.2.7 Clustering by self-organizing map. Created by Kohonen in 1982, the self-organising map (SOM) is an unsupervised learning algorithm. The fundamental characteristic of this algorithm is to reorganize the inputs into a bidimensional space composed of nodes. A SOM, also defined as an atypical neural network, differs from typical artificial neural networks (ANN) in its architecture and its algorithmic properties: it does not learn by backpropagation with SGD (stochastic gradient descent) but uses competitive learning to adjust the weights in
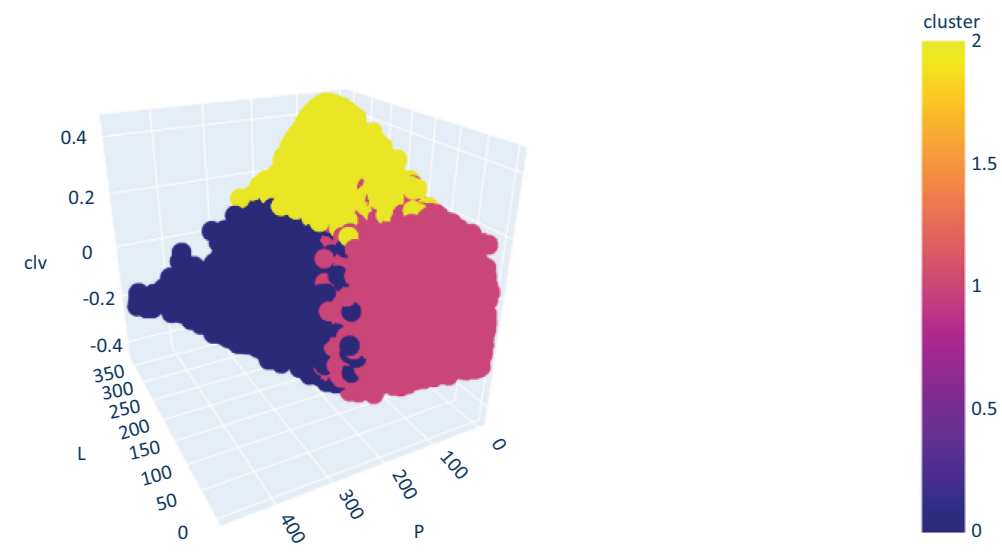

Figure 1. Classification of the clients produced by the $K$-means algorithm. Clients are represented by variables $P$ (periodicity), $L$ (length) and CLV (customer lifetime value) 
neurons. This type of artificial neural networks is used in dimensionality reduction to reduce the data by creating a spatially organized representation. It also helps to discover data correlation (Kohonen et al., 1996).

The structure of SOM is composed of a bidimensional map of neurons, rather than a series of layers. The nodes on this map are all connected directly to the input layer but not to each other. This means that the nodes do not know the values of the other nodes. The grid is the map that organizes itself at each iteration as a function of the input data.

The entire learning process takes place without supervision, which means that no label data is required as the nodes are self-organizing. The SOM is also called self-organizing feature map as the algorithm breaks down all the features in the data into a bidimensional representation and simply creates clusters from the data points based on the similarity between them. In particular, similar data tend to be allocated in the same area of the map.

For this study, a square-shaped map with a total of ten thousand nodes was created. The Euclidean distance has been used to compute the distance between nodes in the map, while the function that weighs the neighborhood of a position in the map is Gaussian. A spread of 0.7 defines the range of dispersion that an input suffers when it is allocated within the map. The random state is set to 13 to allow reproducibility of the results.

Now, it is possible to cluster the data by applying the $K$-means algorithm on the bidimensional space of the map. As before, the $K$-means algorithm is iterated with the random state between ranging from 1 to 10 to ensure consistency. The algorithm produced the output shown in Figure 2.

\subsection{Management}

The case study we analyzed relates to a company operating in the large-scale retail trade specialized in organic and biodynamic products. This company was available to let us analyze the receipts issued by its stores during the period of one year (April 2018-April 2019) within the Rome area.

The company has always been familiar with the concept of sustainability. Sustainability is embodied in its DNA, and it is a constant goal in its strategies, culture and processes.

However, to maintain these company values within a market context characterized by a continuous evolution, the company has continuously invested in research and development.

Figure 2.

Classification of the clients on the selforganizing map

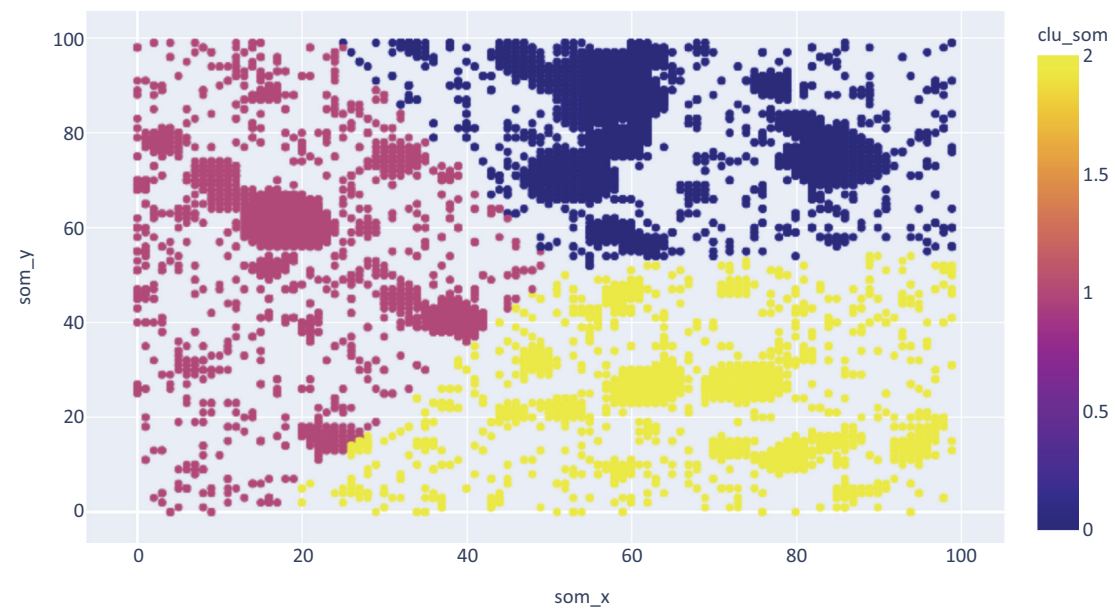


In addition, it had to listen to customers and employees to better understand the evolution driving the market.

The company firmly believes that all manifestations and deepest essence of the human being must be protected, which is independent of his/her role: an employee, a producer, a customer, being part of the community that shares the same values as the company itself.

The human being is the main objective of the company's strategy. This objective offers opportunities to recognize the value of the product and human individuality, which is the essence of the mission that guides the company to offer goods suitable for its evolution. Therefore, the management of this company is interested in reporting customer groups based on their buying patterns, classifying them, recognizing the individual inside the customer base and describing their characteristics to better understand their needs.

Thanks to the segmentation made during this study, it is possible to observe the characteristics of customers through their purchasing patterns. The clusters have been created based on the similarities between the variables. Therefore, it is possible to observe cluster patterns and assume that all customers associated with a cluster exhibit similar behavior. After a description of the characteristics of the cluster, we will explore how these information can be the keys to plan a promotion strategy suited to the needs of each identified group.

\section{Results}

\subsection{Comparison of the two algorithms}

With the clustering produced by both algorithms, we can use the Davies-Bouldin index to compare them before analyzing the clusters obtained.

The $K$-means algorithm produced a clustering with a Davies-Bouldin score of 1.333 , while the self-organizing map produced a clustering with a Davies-Bouldin score of 0.684 . Therefore, the self-organizing map turns out to be the best clustering model.

\subsection{Clusters analysis}

After selecting the most suitable algorithm for customer clustering, the clusters are analyzed in depth. Figure 3 shows the average variable scores of the clusters. On the $x$-axis, there are the three clusters and on the $y$-axis the variable score. The legend shows how each variable from the LRFMP model and the CLV is described by the graph. Thanks to these data, we can compare the characteristics of the clusters to describe their purchasing patterns. To this

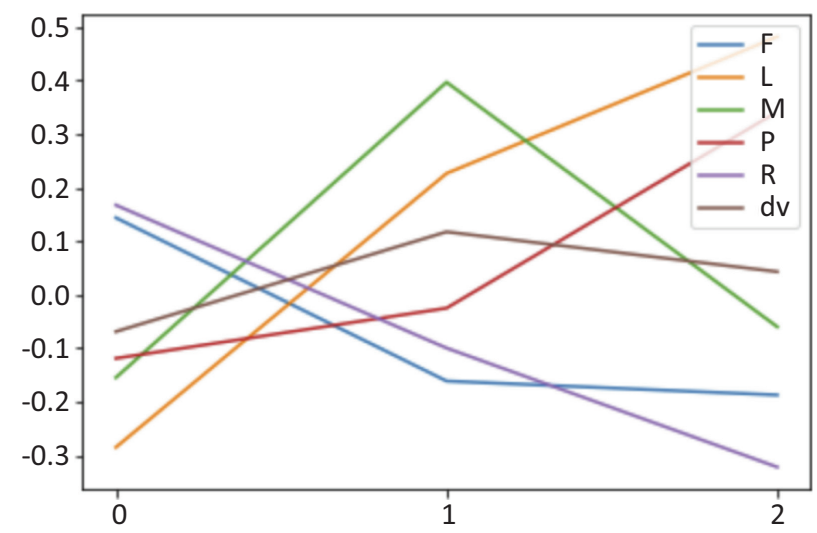

Figure 3.

Clusters average values of each variable of the LRFMP model and CLV score 
purpose, an ANOVA test has been conducted to analyze the differences between clusters in the customer base. Note that the variables $R$ and $p$ are inverted variables, so they are to be interpreted with opposite signs.

Cluster 0 is the less profitable of the three clusters due to the low CLV $(F(2,38,656)=467.87, p=0.00)$. Furthermore, this is confirmed by the low average purchase level $(F(2,38,656)=494.33, p=0.00)$. This cluster appears to be the one that has not long been within the company's customer base according to its $L$ value $(F(2,38,656)=2271.41$, $p=0.00)$ even though the variable $R$ (which is quite high) $(F(2,38,656)=790.40, p=0.00)$ is proving that it is been a while since consumers last visited the store. During the time they were customers, they made frequent visits to the stores $(F(2,38,656)=494.33, p=0.00)$ on a regular basis $(F(2,38,656)=642.42, p=0.00)$.

Cluster 1 is the one more profitable of the three clusters according to the high CLV level $(F(2,38,656)=467.87, p=0.00)$. This seems to depend by the amount of average purchase spend is high $(F(2,38,656)=494.33, p=0.00)$ compared to the other two clusters and on the fact that those customers have a long relationship with the company $(F(2,38,656)=2271.41$, $p=0.00)$. The latest purchase was relatively recent $(F(2,38,656)=790.40, p=0.00)$, and purchase patterns were fairly regular $(F(2,38,656)=642.42, p=0.00)$ but infrequent $(F(2,38,656)=494.33, p=0.00)$.

Cluster 2 is composed of customers who have had a long relationship with the company $(F(2,38,656)=2271.41, p=0.00)$ and who currently seem to have bought something in the last period $(F(2,38,656)=790.40, p=0.00)$. Their purchases are irregular $(F(2,38,656)=642.42$, $p=0.00)$ and less frequent $(F(2,38,656)=494.33, p=0.00)$ than the other clusters. Their spending level $(M)$ is on average $(F(2,38,656)=494.33, p=0.00)$ as well as their CLV $(F(2,38,656)=467.87, p=0.00)$.

\subsection{Managerial implication}

Now that the three clusters have been identified and described, it is possible to use this information to better understand customers.

In marketing, customer personas are one of the most useful tools often used alongside market segmentation. A persona is a fictional entity that describes a market segment based on its characteristics (Lidwell et al., 2010). This fictional entity is detailed according to what is known about that segment and other fictional details to make it more believable. This tool aims to create an entity that is easier to interface with when planning marketing strategies.

This expedient might seem redundant, but it shows how the company cares about its customers and also emphasizes the ability to create a personal connection with customers (Jenkinson, 2006).

The customer segments that have been highlighted during this study are three, and all have distinctive characteristics.

Cluster 0 represents the cluster of all those customers who started the period as customers but, since their last purchase was not recent, they have probably fallen down. In addition, their relationship with the company was regular, and they went into the store many times to buy some inexpensive products or very specific products that were hard to find elsewhere. A persona named John has been created to describe cluster 0 . He is a student with a part-time job. When he gets home, he enters the shop to buy just a couple of specific products such as organic products or eco-organic personal hygiene products.

Cluster 1 represents the highest value customer cluster within the customer base. They have been customers for a long time and spend a significant amount of money on average. Their visits to the company's stores are regular but infrequent, and the last visit was recently. A persona named Mike has been created to describe cluster 1 . Mike is a family man with an adequate salary and a set of values that are compatible or in line with the ones of the 
company. He buys many products such as food and other consumer items for the whole family. He continues to shop at the company's stores as he strongly believes in the values of sustainable products and the consumption of organic foods and is willing to pay a little more to bring home sustainable quality products.

Cluster 2 is composed of the customers who regularly spend in stores and have the longest relationship with the company. Their latest purchase happened recently even though they did not go to the store often. This cluster, which represents the second most valuable, is described by the persona named Mary. Mary usually does her regular shopping for food and other items at other stores and waits for occasional discounts in the company's stores to purchase different products. She is in line with the company's values and respects them, but her willingness to pay is not strong enough to be a constant buyer. The discounts lower the barrier of Mary's perceived price barrier on the company's products, so willingness to pay is enough to place the company at the top of her consideration.

\section{Discussion}

Based on the description of a persona, a specific marketing strategy can be planned to improve the value shared between the company and its customers.

For Mike (cluster 1), which represents the most valuable segment and, according to the analysis, the most loyal one, designing promotions is unlikely to further increase his value. However, at this stage of the relationship, it is important to treat loyal customers based on their status. This means that the company must recognize their loyalty. Therefore, investing in advanced customer support for this type of customer could be productive to implement their retention into the customer base.

For Mary (cluster 2), the barrier to a regular and frequent level of buying is willingness to buy. Discounts are a good strategy for luring these longtime customers to the store but is not a permanent solution. Perhaps the launch of a more accessible product line could motivate Mary to choose the company's store more often than others. However, this solution could carry risks because, in developing new products solutions, the firm must be consistent with its values. Furthermore, since quality is one of them, developing a more accessible product line might not be possible without interfering with the company' quality standards.

For John (cluster 0), the marketing strategy is not intended to increase the delivered value but to win him back as a customer. As already said, John represents the segment that is similar to having churned. At this point, the only chance the company has to win back its lost client is to understand the motivation behind their abandonment and see if it can be fixed whatever problem John has encountered. Once the problem has been addressed and solved, it is time for a call to action with a specific communication trying to regain the customer's trust.

From an academic point of view, this methodology opens up the possibility of better exploring the synergy created by the integration between different fields. Thanks to the CAM methodology, it is possible to build solutions that can withstand major problems in different areas where the integration of different knowledge is required to be successful. Research can greatly benefit from CAM methodology.

\section{Conclusions}

This study originated from the need for companies to use modern technologies and data analytics to implement their market strategies.

Nowadays, the business reality is declared to be more focused on customers before profits. This approach creates a sustainable value in which the customer feels privileged, important and considered. This attitude is much more profitable if it is part of a consistent marketing communication that is not limited to just customers but extends to all stakeholders. By
CAM of the customer lifetime value

$\longrightarrow$


following the company mission, for example, employees must be able to live a true community experience with all the people involved in the company.

Producers of goods sold by the company must be able to offer customers goods of the highest quality of life. At the same time, producers should share the value of caring for the earth that belongs to no one but to everyone.

The customer must be respected in his needs and ideals. Therefore, the customer must take a central position for the company; it is the first contact with its environment. If the company wants to spread its ideals and values, customers are the first category of stakeholders to deal with. This is why it is essential to build a relationship based on solid loyalty with customers. Analyzing the value of consumers by applying the latest machine learning algorithms allows the manager, who observes the data, to understand, predict and manage the needs of consumers. This study illustrates how these new technologies can innovate the environment of a modern enterprise through different approaches. That type of innovation process requires different fields of knowledge such as consumer behavior, artificial intelligence and marketing strategy. That is why the CAM (cognitive analytics management) methodology has been applied by bringing together different fields to describe the different implications of the study.

Using the machine learning algorithm of the self-organizing map it was possible to identify three clusters within the available dataset. The CLV has been then calculated using an LRFMP model to identify clusters of customers with similar purchasing patterns. This approach simplifies the job of the manager who now can easily plan a marketing strategy for each identified customer group.

It should also be noted that, due to the specificity of the data, the results of this method are strictly applicable to the aforementioned company. However, this does not exclude the application of the method itself to sectors other than large-scale distribution, as long as the interest is to better analyze the customer base, obtain valuable information and maximize the value offered.

\section{References}

Aljawarneh, N. and Al-Omari, Z. (2018), "The role of enterprise resource planning systems ERP in improving customer relationship management CRM: an empirical study of safeway company of Jordan”, International Journal of Business and Management, Vol. 13 No. 8, pp. 86-100.

Arthur, D. and Vassilvitskii, S. (2006), K-Means++: The Advantages of Careful Seeding, Stanford, San Francisco.

Barton, D. and Court, D. (2012), "Making advanced analytics work for you", Harvard Business Review, Vol. 90 No. 10, pp. $78-83$.

Berkhin, P. (2006), “A survey of clustering data mining techniques”, Grouping Multidimensional Data, Springer, pp. 25-71.

Boulding, W., Staelin, R., Ehret, M. and Johnston, W.J. (2005), “A customer relationship management roadmap: what is known, potential pitfalls, and where to go", Journal of Marketing, SAGE Publications Sage CA, Los Angeles, CA, Vol. 69 No. 4, pp. 155-166.

Bygstad, B. and Presthus, W. (2012), “'Social media as CRM? How two airline companies used Facebook during the 'Ash crisis' in 2010"', Scandinavian Journal of Information Systems, Vol. 25 No. 1, pp. 1-22.

Chalmeta, R., Campos, C. and Grangel, R. (2001), "References architectures for enterprise integration”, Journal of Systems and Software, Elsevier, Vol. 57 No. 3, pp. 175-191.

Davenport, T.H., Barth, P. and Bean, R. (2012), “How 'big data' is different”, MIT Sloan Management Review, Vol. 54 No. 1, pp. 22-24. 
Davies, D.L. and Bouldin, D.W. (1979), "A cluster separation measure”, IEEE Transactions on Pattern Analysis and Machine Intelligence, IEEE No. 2, pp. 224-227.

Di Taranto, G. (2013), La Globalizzazione Diacronica, G Giappichelli Editore, Rome.

Dwyer, F.R. (1997), "Customer lifetime valuation to support marketing decision making”, Journal of Direct Marketing, Wiley Online Library, Vol. 11 No. 4, pp. 6-13.

Fader, P.S. and Hardie, B.G. (2009), "Probability models for customer-base analysis", Journal of Interactive Marketing, Elsevier, Vol. 23 No. 1, pp. 61-69.

Fader, P.S., Hardie, B.G. and Lee, K.L. (2005), "RFM and CLV: using iso-value curves for customer base analysis", Journal of Marketing Research, SAGE Publications Sage CA, Los Angeles, CA, Vol. 42, No. 4, pp. 415-430.

Galitsky, B. and de la Rosa, J.L. (2011), "Concept-based learning of human behavior for customer relationship management”, Information Sciences, Elsevier, Vol. 181 No. 10, pp. 2016-2035.

Greenberg, P. (2003), “A commonwealth of self-interest”, CRM Magazine, Vol. 7, pp. 10-26.

Gummesson, E. (2002), "Relationship marketing in the new economy", Journal of Relationship Marketing, Taylor and Francis, Vol. 1 No. 1, pp. 37-57.

Holbrook, M.B. (1994), "The nature of customer value: an axiology of services in the consumption experience", Service Quality: New Directions in Theory and Practice, Thousand Oaks, CA, Vol. 21 No. 1, pp. 21-71.

Hughes, A.M. (2000), Strategic Database Marketing: The Masterplan for Starting and Managing a Profitable, Customer-Based Marketing Program, McGraw-Hill, New York, NY, Vol. 12.

Iriana, R. and Buttle, F. (2006), Customer Relationship Management (CRM) System Implementations: An Assessment of Organisational Culture, University of Illinois Research Park, Common Ground Publishing, Champaign.

Jao, C. (2010), Decision Support Systems, BoD-Books on Demand, InTechOpen, London.

Jenkinson, A. (2006), "Do organisations now understand the importance of information in providing excellent customer experience?", Journal of Database Marketing and Customer Strategy Management, Springer, Vol. 13 No. 4, pp. 248-260.

Jian, K.E. (2004), Integration of ERP and CRM Together with Effect on DSS [J], Journal of Beijing Technology and Business University, Bejing, Vol. 4.

Kayande, U., De Bruyn, A., Lilien, G.L., Rangaswamy, A. and van Bruggen, G.H. (2006), The Effect of Feedback and Learning on Dss Evaluations, ERIM Report Series Research in Management (Ref. ERS-2006-001-MKT), Rotterdam.

Kim, S.Y., Jung, T.S., Suh, E.H. and Hwang, H.S. (2006), "Customer segmentation and strategy development based on customer lifetime value: a case study", Expert Systems with Applications, Elsevier, Vol. 31 No. 1, pp. 101-107.

Kohonen, T. (1990), "The self-organizing map", Proceedings of the IEEE, IEEE, Vol. 78 No. 9, pp. 1464-1480.

Kohonen, T., Oja, E., Simula, O., Visa, A. and Kangas, J. (1996), "Engineering applications of the selforganizing map", Proceedings of the IEEE, IEEE, Vol. 84 No. 10, pp. 1358-1384.

Kotler, P., Keller, K.L., Ancarani, F. and Costabile, M. (2014), Marketing Management 14/e, Pearson.

Kumar, V. and Reinartz, W. (2016), "Creating enduring customer value", Journal of Marketing, American Marketing Association, Vol. 80 No. 6, pp. 36-68.

Leuthesser, L. and Kohli, A.K. (1995), "Relational behavior in business markets: implications for relationship management”, Journal of Business Research, Elsevier, Vol. 34 No. 3, pp. 221-233.

Lidwell, W., Holden, K. and Butler, J. (2010), Universal Principles of Design, Revised and Updated: 125 Ways to Enhance Usability, Influence Perception, Increase Appeal, Make Better Design Decisions, and Teach through Design, Rockport Pub, Beverly, MA. 
Lloyd, S. (1982), "Least squares quantization in PCM", IEEE Transactions on Information Theory, IEEE, Vol. 28 No. 2, pp. 129-137.

MacQueen, J. (1967), "Some methods for classification and analysis of multivariate observations", Proceedings of the Fifth Berkeley Symposium on Mathematical Statistics and Probability, Oakland, CA, Vol. 1, pp. 281-297.

Maryani, I. and Riana, D. (2017), "Clustering and profiling of customers using RFM for customer relationship management recommendations", 2017 5th International Conference on Cyber and IT Service Management (CITSM), IEEE, pp. 1-6.

Osman, I.H. and Anouze, A.L. (2014), "A cognitive analytics management framework (CAM-Part 1): SAMAS components, leadership, frontier performance growth, and sustainable shared value", Handbook of Research on Strategic Performance Management and Measurement Using Data Envelopment Analysis, IGI Global, pp. 1-79.

Osman, I.H., Anouze, A.L., Irani, Z., Lee, H., Medeni, T.D. and Weerakkody, V. (2019), “A cognitive analytics management framework for the transformation of electronic government services from users' perspective to create sustainable shared values", European Journal of Operational Research, Elsevier, Vol. 278 No. 2, pp. 514-532.

Peker, S., Kocyigit, A. and Eren, P.E. (2017), "LRFMP model for customer segmentation in the grocery retail industry: a case study", Marketing Intelligence and Planning, Emerald Publishing, Vol. 35 No. 4, pp. 544-559.

Pfeifer, P.E., Haskins, M.E. and Conroy, R.M. (2005), "Customer lifetime value, customer profitability, and the treatment of acquisition spending", Journal of Managerial Issues, JSTOR, pp. 11-25.

Power, C., Konrad, W., Cuneo, A.Z. and Treece, J.B. (1991), "Value marketing: quality, service, and fair pricing are the keys to selling in the'90s”, Business Week, Vol. 11 No. 4, pp. 132-140.

Rahimi, R. and Kozak, M. (2017), "Impact of customer relationship management on customer satisfaction: the case of a budget hotel chain", Journal of Travel and Tourism Marketing, Taylor and Francis, Vol. 34 No. 1, pp. 40-51.

Rollins, M. and Halinen, A. (2005), "Customer knowledge management competence: towards a theoretical framework", Proceedings of the 38th Annual Hawaii International Conference on System Sciences, IEEE, p. 240a.

Ryals, L. and Knox, S. (2001), "Cross-functional issues in the implementation of relationship marketing through customer relationship management”, European Management Journal, Elsevier, Vol. 19 No. 5, pp. 534-542.

Spagnoletti, P., Resca, A. and Lee, G. (2015), "A design theory for digital platforms supporting online communities: a multiple case study", Journal of Information Technology, SAGE Publications Sage, London, Vol. 30 No. 4, pp. 364-380.

Stephens-Davidowitz, S. and Pabon, A. (2017), Everybody Lies: Big Data, New Data, and what the Internet Can Tell Us about Who We Really Are, HarperCollins, New York, NY.

Stone, B. (1995), Successful Direct Marketing Methods, NTC BusinessBooks, Lincolnwood, IL, pp. $37-57$.

Tkachenko, Y. (2015), "Autonomous CRM control via CLV approximation with deep reinforcement learning in discrete and continuous action space", arXiv preprint arXiv:1504.01840.

Ulaga, W. and Chacour, S. (2001), "Measuring customer-perceived value in business markets: a prerequisite for marketing strategy development and implementation", Industrial Marketing Management, Elsevier, Vol. 30 No. 6, pp. 525-540.

Yi, Y. and Gong, T. (2013), “Customer value co-creation behavior: scale development and validation”, Journal of Business Research, Elsevier, Vol. 66 No. 9, pp. 1279-1284.

Za, S. (2018), Internet of Things: Persone, Organizzazioni e Società 4.0, Luiss University Press, Roma.

Zeithaml, V.A. (1988), "Consumer perceptions of price, quality and value: a means-end model and synthesis of evidence", Journal of Marketing, Vol. 52, pp. 2-22. 
Zerbino, P., Aloini, D., Dulmin, R. and Mininno, V. (2018), "Big data-enabled customer relationship management: a holistic approach", Information Processing and Management, Vol. 54 No. 5, pp. 818-846.

CAM of the customer lifetime value

\section{Further reading}

Corporation, M. (2019), "What is CRM?| microsoft dynamics 365”, available at: https://dynamics. microsoft.com/en-us/crm/what-is-crm/ (accessed 8 August 2020).

Davenport, T.H. and Prusak, L. (1998), Working Knowledge: How Organizations Manage what They Know, Harvard Business Press, Cambridge.

Deighton, J.A., Rizley, R. and Keane, S. (2012), Research Priorities of the Marketing, Science Institute, Cambridge, 2012-2014.

D’Atri, A., Ferrara, M., George, J.F. and Spagnoletti, P. (2011), Information Technology and Innovation Trends in Organizations: ItAIS: The Italian Association for Information Systems, Springer Science and Business Media, Roma.

Jain, A.K. (2010), "Data clustering: 50 years beyond K-means", Pattern Recognition Letters, Elsevier, Vol. 31 No. 8, pp. 651-666.

Kao, I.W., Tsai, C.Y. and Wang, Y.C. (2007), "An effective particle swarm optimization method for data clustering", 2007 IEEE International Conference on Industrial Engineering and Engineering Management, IEEE, pp. 548-552.

Linoff, G.S. and Berry, M.J. (2011), Data Mining Techniques: For Marketing, Sales, and Customer Relationship Management, John Wiley and Sons, Hoboken.

Oh, H. (1999), "Service quality, customer satisfaction, and customer value: a holistic perspective", International Journal of Hospitality Management, Elsevier, Vol. 18 No. 1, pp. 67-82.

Parasuraman, A. (1997), "Reflections on gaining competitive advantage through customer value", Journal of the Academy of Marketing Science, Springer, Vol. 25 No. 2, p. 154.

Peters, L.D., Pressey, A.D. and Greenberg, P. (2010), "The impact of CRM 2.0 on customer insight", Journal of Business and Industrial Marketing, Emerald Group Publishing, Vol. 25 No. 6 , pp. 410-419.

Rahimi, R. (2017), "Customer relationship management (people, process and technology) and organisational culture in hotels", International Journal of Contemporary Hospitality Management, Emerald Publishing, Vol. 29 No. 5, pp. 1380-1402.

Reinartz, W.J. and Kumar, V. (2000), "On the profitability of long-life customers in a noncontractual setting: an empirical investigation and implications for marketing", Journal of Marketing, Vol. 64 No. 4, pp. 17-35, SAGE Publications Sage CA, Los Angeles, CA.

Reinartz, W.J. and Kumar, V. (2003), "The impact of customer relationship characteristics on profitable lifetime duration”, Journal of Marketing, SAGE Publications Sage CA, Los Angeles, CA, Vol. 67 No. 1, pp. 77-99.

Rust, R.T., Lemon, K.N. and Zeithaml, V.A. (2004), "Return on marketing: using customer equity to focus marketing strategy", Journal of Marketing, SAGE Publications Sage CA, Los Angeles, CA, Vol. 68 No. 1, pp. 109-127.

Setijono, D. and Dahlgaard, J.J. (2007), "Customer value as a key performance indicator (KPI) and a key improvement indicator (KII)", Measuring Business Excellence, Emerald Group Publishing, Vol. 11 No. 2, pp. 44-61.

Soltani, Z., Zareie, B., Milani, F.S. and Navimipour, N.J. (2018), "The impact of the customer relationship management on the organization performance", The Journal of High Technology Management Research, Vol. 29 No. 2, pp. 237-246.

Vesanto, J. and Alhoniemi, E. (2000), "Clustering of the self-organizing map”, IEEE Transactions on Neural Networks, IEEE, Vol. 11 No. 3, pp. 586-600. 
Wang, Y.-J. (2010), “A clustering method based on fuzzy equivalence relation for customer relationship management”, Expert Systems with Applications, Elsevier, Vol. 37 No. 9, pp. 6421-6428.

Xu, Y., Yen, D.C., Lin, B. and Chou, D.C. (2002), "Adopting customer relationship management technology", Industrial Management and Data Systems, Vol. 102 No. 8, pp. 442-452.

\section{Corresponding author}

Antonio Miloso can be contacted at: antonio.miloso@expertlab.it

For instructions on how to order reprints of this article, please visit our website: www.emeraldgrouppublishing.com/licensing/reprints.htm Or contact us for further details: permissions@emeraldinsight.com 